\title{
Qualidade do fruto do coqueiro anão verde em função de nitrogênio e potássio na fertirrigação ${ }^{1}$
}

\author{
Miguel Ferreira Neto ${ }^{2}$, José S. de Holanda ${ }^{3}$, Marcos V. Folegatti ${ }^{4}$, Hans R. Gheyi ${ }^{5}$, Walter E. Pereira ${ }^{6}$ \& Lourival F. Cavalcante ${ }^{6}$
}

\section{RESUMO}

Objetivou-se, com este trabalho, estudar os efeitos de doses de $\mathrm{N}$ e K fornecidos via fertirrigação na qualidade de frutos de coco (Cocos nucifera L.) cultivar Anão Verde do Jiqui, com 7 anos de cultivo, em Neossolo Quartizarênico dos tabuleiros costeiros. O estudo foi conduzido no município de Parnamirim, RN, no período de abril de 2003 a março de 2004, em blocos ao acaso, com 4 repetições. Para composição dos tratamentos utilizou-se a matriz experimental Plan Puebla III, composta da combinação de doses de nitrogênio e de potássio, cujas fontes foram a uréia e o cloreto de potássio, respectivamente, obtendo-se 10 tratamentos no intervalo de 256 a $4874 \mathrm{~g} \mathrm{planta}^{-1} \mathrm{ano}^{-1}$ de $\mathrm{N}$ e de 258 a 4872 g planta $^{-1}$ ano $^{-1}$ de $\mathrm{K}_{2} \mathrm{O}$ aplicados via fertirrigação por microaspersão. A qualidade do fruto foi avaliada com base no peso médio, volume de água, ${ }^{\circ}$ Brix e salinidade (condutividade elétrica) da água de coco. O peso médio do fruto não foi influenciado pelas doses de $\mathrm{N}$ e $\mathrm{K}$ aplicadas e aumento das doses de $\mathrm{N}$ provocaram redução do volume, do ${ }^{\circ}$ Brix e elevaram o pH da água, enquanto as doses de $\mathrm{K}$ reduziram a salinidade e aumentaram o ${ }^{\circ}$ Brix da água de coco.

Palavras-chave: Cocos nucifera L., irrigação, água de coco, nutrição mineral

\section{Quality of green fruits of "anão verde" coconut in relation to doses of nitrogen and potassium via fertigation}

\begin{abstract}
The objective of this study was to evatuate the effects of doses of $\mathrm{N}$ and $\mathrm{K}$ applied via fertigation on quality of green fruits of coconut (Cocos nucifera L.) cultivar Anão Verde of Jiqui, 7 years old in a Quartzarenic Neosol of Coastal Table Lands. The study was carried out in the municipality of Parnamirim, in the State of Rio Grande do Norte - Brazil, during April, 2003 to March, 2004. The experiment was conducted in a randomized block, using for the combination of treatments the Plan Puebla III experimental matrix, consisting of 10 combinations of doses of nitrogen and potassium supplied through urea and potassium chloride, respectively. The doses of $\mathrm{N}$ varied from 256 to $4874 \mathrm{~g} \mathrm{plant}^{-1}$ year $^{-1}$ and that of $\mathrm{K}_{2} \mathrm{O}$ from 258 to 4872 g plant $^{-1}$ year ${ }^{-1}$ applied via fertigation by micro-sprinkler irrigation system. The quality of green fruits was evaluated on the basis of mean weight of fruit, volume of water, ${ }^{\circ}$ Brix, $\mathrm{pH}$ and salinity (electrical conductivity) of the coconut water. The mean weight of fruit was not influenced by the application of $\mathrm{N}$ and $\mathrm{K}$ in fertigation. The increase in dose of $\mathrm{N}$ decreased the volume and ${ }^{\circ} \mathrm{Brix}$ and increased $\mathrm{pH}$ of the coconut water, while increase in dose of $\mathrm{K}$ decreased the salinity and increased ${ }^{\circ}$ Brix of coconut water.
\end{abstract}

Key words: Cocos nucifera L., irrigation, coconut water, mineral nutrition

\footnotetext{
1 Parte da Tese de Doutorado do primeiro autor, apresentada à ESALQ/USP

2 UFERSA, BR 110, km 47, CP 137, CEP 59625-900, Mossoró, RN. Fone: (84) 3315-1741. E-mail: miguel@ufersa.edu.br

3 EMPARN/EMBRAPA, CP 59, CEP 59020-390, Natal, RN. Fone: (84) 3221-2301, E-mail: simplicioemparn@rn.gov.br

${ }^{4}$ DER-ESALQ/USP, CP 9, CEP 13418-900, Piracicaba, SP. Fone: (19) 3429-4217, E-mail: mvfolega@esalq.usp.br

${ }^{5}$ UAEAg/UFCG, CP 10 056, CEP 58109-930, Campina Grande, PB. Telefax: (83) 3310-1056. E-mail: hans@deag.ufcg.edu,br

${ }_{6}^{6}$ CCA/UFPB, CEP 58397-000, Areia, PB. Fone: (83) 3362-2300. E-mail: walter@cca.ufpb.br; lofeca1946@yahoo.com.br
} 


\section{INTRODUÇÃO}

A exploração do coqueiro (Cocos nucifera, L.) tem evoluído na maioria dos estados brasileiros, cobrindo áreas das regiões Norte, Nordeste, Sudeste e Centro-Oeste, cujo crescimento se deve sobretudo ao aumento da demanda pelo fruto verde, com interesse comercial na água do coco para consumo in natura e uso na indústria de envasamento, ocupando espaço no vultoso mercado de refrigerantes. Nos plantios comerciais destinados ao mercado de água no Brasil predomina a variedade Anã, em virtude da sua boa performance, em termos de rendimento e qualidade da água de coco.

Na maioria dos países produtores o coco é utilizado para a produção de óleo, contendo aproximadamente 50\% em ácido láurico, característica esta que lhe confere boa cotação no mercado de cosméticos. A inclusão da cultura do coqueiro entre as oleaginosas com potencial para produção de biodiesel no Brasil constitui-se, portanto, em uma alternativa a ser analisada pelos órgãos de desenvolvimento reforçando, assim, a necessidade de implementação de um programa de revitalização da cultura, sob pena de não ser atendido o significativo aumento da demanda de matériaprima (Fontes, 2006).

O Brasil é o quarto maior produtor de coco, representando 5\% da produção mundial, enquanto para consumo de água é o maior produtor de coco verde do mundo (FAO, 2005), sobressaindo-se a região Nordeste, com 85,6\% da produção nacional da cultura com área plantada, em 2002 de aproximadamente 280.835 ha (Anuário Estatístico do Brasil, 2004). No Nordeste do Brasil, o coqueiro encontra ambiente favorável ao seu pleno desenvolvimento vegetativo e potencial produtivo, favorecendo sua expansão nesa região.

Cerca de 90.000 ha correspondem à variedade Anão, dos quais menos de $50 \%$ se encontravam em produção efetiva no ano de 2005. A produção nacional, que em 1999 era de 280 milhões de cocos, pode ter atingido, em 2005, um bilhão de frutos; com esta expansão, os produtores pretendem aumentar o consumo de água de coco, de pouco mais de $1 \%$ para 5\% em relação ao consumo de refrigerantes, que é de aproximadamente $10 \times 10^{9}$ de $\mathrm{L}_{\text {ano- }}{ }^{1}$. A expansão da industrialização reflete, ainda, o grande aumento da produção do coco Anão, variedade indicada para a produção de água e, nesta perspectiva, o coqueiro se consolidará como uma das mais importantes frutícolas permanentes cultivadas.

Embora o coqueiro Anão irrigado venha aumentando sua participação na cocoicultura brasileira, os rendimentos médios para o cultivo irrigado dessa variedade nos $6^{\circ}$ e $7^{\circ}$ anos de cultivo, ficam em torno de 32 e 54 frutos planta ${ }^{-1}$ ano $^{-1}$, respectivamente (Anuário Estatístico do Brasil, 2004). As causas da baixa produtividade são a idade de cultivo, a baixa fertilidade dos solos, o déficit hídrico proporcionado pelo manejo inadequado de irrigação e o controle pouco eficiente de pragas e doenças. A cultura também sofre em condições de umidade relativa muito elevada devido à propagação de doenças fúngicas e redução na absorção de nutrientes, ocasionando queda prematura dos frutos (Menon \& Paladai, 1958).

A adubação é uma das práticas de expressivo impacto na produtividade do coqueiro. O coqueiro é nutricionalmente exigente e necessita de grandes quantidades de nutrientes para a formação de frutos (Malavolta et al., 1974); dentre os nutrientes, o potássio e o nitrogênio são extraídos do solo em maior quantidade, seguidos do cloro, fósforo, magnésio, enxofre e cálcio (Ouvrier, 1984). De acordo com Sobral (1998) a prática de adubação é de maior impacto sobre a produtividade do coqueiro em algumas regiões do Nordeste, sobretudo em solos de baixa fertilidade, uma vez que o crescimento contínuo do coqueiro implica na remoção de grandes quantidades de nutrientes, os quais devem ser repostos por meio de aplicações periódicas (Sobral, 2003). Conforme Magat (2005) a absorção de $\mathrm{N}, \mathrm{P}_{2} \mathrm{O}_{5}$ e $\mathrm{K}_{2} \mathrm{O}$ pelo coqueiro é da ordem de 174,46 e $299 \mathrm{~kg} \mathrm{ha}^{-1} \mathrm{ano}^{-1}$, respectivamente, sendo que cerca de $62 \%$ do $\mathrm{N}, 84 \%$ do P e $78 \%$ do K são exportados pelo fruto.

A maioria dos estudos de adubação do coqueiro foi realizada em condições edafoclimáticas da Ásia, com a variedade gigante, que tem o consumo voltado para a produção de coco seco. No cultivo de coco irrigado com a mesma tendência de outras culturas, vem aumentando a utilização da fertirrigação, técnica que pode, pela sua eficiência de aplicação e fracionamento das doses, aumentar a produtividade, melhorar a qualidade dos frutos e contribuir para a estabilização da oferta, para suprir a uma demanda sempre crescente (Papadoupolus, 2001).

Considerando a importância do fornecimento de nitrogênio e potássio para o cultivo de coco verde, através da técnica de fertirrigação, realizou-se este trabalho com o objetivo de avaliar o efeito de doses de nitrogênio e potássio sobre a qualidade de frutos verdes, com vista ao mercado de água de coco.

\section{MATERIAL E MÉTODOS}

O experimento foi conduzido no Campo Experimental do Jiqui, pertencente à Empresa de Pesquisa Agropecuária do Rio Grande do Norte (EMPARN), Parnamirim, RN, situado nas coordenadas geográficas de $5^{\circ} 46^{\prime}$ de Latitude S e $35^{\circ} 12^{\prime}$ de Longitude W, em um pomar de coqueiro (Cocos nucifera L.) cultivar Anão Verde do Jiqui, com 7 anos de idade. Segundo a classificação de Wilhelm Köppen, o clima da região é do tipo As', ou seja, tropical chuvoso com verão seco e estação chuvosa adiantando-se para o outono, temperatura média anual de $28{ }^{\circ} \mathrm{C}$ e precipitação média anual variando de 1500 a $1800 \mathrm{~mm}$. O pomar foi implantado em um espaçamento triangular de 7,5 m em solo dos tabuleiros costeiros classificado como Neossolo Quartzarênico (Santos et al., 2006), tendo a areia representado $956 \mathrm{~g} \mathrm{~kg}^{-1}$ da granulometria, com pH 5,9; cálcio, magnésio e alumínio trocáveis respectivamente de 0,67; 0,14 e 0,04 $\mathrm{cmol}_{\mathrm{C}} \mathrm{kg}^{-1}$, matéria orgânica de $12,8 \mathrm{~g} \mathrm{~kg}^{-1}$ e fósforo, potássio e sódio, respectivamente, de 16 , 15 e $13 \mathrm{mg} \mathrm{kg}^{-1}$, determinados conforme metodologias recomendadas pela EMBRAPA (1997).

O delineamento foi em blocos ao acaso, com 4 repetições empregando-se, para composição dos tratamentos, a matriz experimental Plan Puebla III, composta da combinação de 
dois fatores: doses de nitrogênio e de potássio, a partir da uréia e o cloreto de potássio, respectivamente, obtendo-se 10 tratamentos e se definindo o intervalo para as doses de $\mathrm{N}$ entre 256 e 4874 g planta $^{-1}$ ano $^{-1}$ e de $\mathrm{K}_{2} \mathrm{O}$ variando entre 258 e 4872 g planta $^{-1}$ ano $^{-1}$ (Tabela 1) aplicados via fertirrigação, por microaspersão.

Tabela 1. Relação de tratamentos e respectivas doses de nitrogênio e potássio, aplicadas por ano na fertirrigação

\begin{tabular}{|c|c|c|c|c|c|c|}
\hline \multirow{2}{*}{ Trat. } & \multicolumn{2}{|c|}{ Nivel } & \multicolumn{4}{|c|}{ Dose - g planta ${ }^{-1}$ ano $^{-1}$} \\
\hline & A & B & $\mathbf{N}$ & $\mathrm{K}_{2} \mathrm{O}$ & Uréia & $\mathrm{KCl}$ \\
\hline 1 & $-0,4$ & $-0,4$ & 1540 & 1539 & 3420 & 2565 \\
\hline 2 & $-0,4$ & 0,4 & 1540 & 3591 & 3420 & 5985 \\
\hline 3 & 0,4 & $-0,4$ & 3591 & 1539 & 7980 & 2565 \\
\hline 4 & 0,4 & 0,4 & 3591 & 3591 & 7980 & 5985 \\
\hline 5 & $-0,9$ & $-0,4$ & 256 & 1539 & 570 & 2565 \\
\hline 6 & 0,9 & 0,4 & 4874 & 3591 & 10830 & 5985 \\
\hline 7 & $-0,4$ & $-0,9$ & 1540 & 258 & 3420 & 430 \\
\hline 8 & 0,4 & 0,9 & 3591 & 4872 & 7890 & 8120 \\
\hline 9 & 0,0 & 0,0 & 2565 & 2565 & 5700 & 4275 \\
\hline 10 & $-0,9$ & $-0,9$ & 256 & 258 & 570 & 430 \\
\hline
\end{tabular}

A área útil experimental se compunha de 200 plantas distribuídas em aproximadamente 1,6 ha com parcelas formadas por 10 plantas, dentre as quais 5 úteis e uma bordadura externa circundando o experimento. A água utilizada na irrigação das plantas foi proveniente da Lagoa de Jiqui, possui, conforme Ayers \& Westcot (1999), baixos riscos de salinidade (condutividade elétrica $=0,1 \mathrm{dS} \mathrm{m}^{-1}$ ) e de sodicidade (relação de adsorção de sódio $\left.=0,83 \mathrm{~m} \mathrm{~mol} \mathrm{~L}^{-1}\right)^{1 / 2}$.

Utilizaram-se, na fertirrigação, microaspersores autocompensantes com vazão nominal de $53 \mathrm{~L} \mathrm{~h}^{-1}$, os quais operaram à pressão de $150 \mathrm{kPa}$, proporcionando um raio molhado de 3,0 m; cada planta dispunha de um emissor, perfazendo o total de 10 microaspersores por linha lateral, montados ao longo das linhas de plantio, a $50 \mathrm{~cm}$ de distância, em posição paralela ao estipe. Na entrada de cada parcela (linha lateral) foi colocado um registro, cuja montagem permitiu que os tratamentos fossem isolados para entrada de fertilizantes somente nas linhas laterais desejadas. A fertirrigação foi realizada com o auxílio de uma bomba centrífuga, injetora de fertilizantes. A quantidade de nutrientes foi dividida em 52 aplicações durante o experimento correspondendo às semanas de cultivo do ensaio, fertirrigando-se diariamente dois tratamentos e se completando as 10 aplicações na área em 5 dias.

De acordo com a programação de fertirrigação e com o tratamento, a solução foi preparada dissolvendo-se as quantidades de fertilizantes calculadas em $100 \mathrm{~L}$ de água com antecedência e se deixando em repouso pelo menos durante 20 min, seguido do bombeamento para o sistema de irrigação, com tempo mínimo de distribuição de $30 \mathrm{~min}$, conforme recomendações de Frizone et al. (1985).

A freqüência de irrigação foi diária, durante todo o período de estudo, suspenso apenas nos dias em que ocorriam precipitações superiores a $10 \mathrm{~mm}$. Caracterizou-se a demanda hídrica atmosférica da região a partir de dados metereologi- cos - temperatura do ar, insolação, umidade relativa do ar e velocidade do vento. O volume de água aplicado foi estimado a partir da evapotranpiração de referência (ETo) calculada pelo modelo de Penman-Montheith (Allen et al., 1998) e o coeficiente da cultura (Kc). No presente estudo, o valor do Kc adotado foi igual a 1,0, em virtude dos ensaios realizados anteriormente na área, revelaram uma correlação climática melhor com o uso deste valor, ao invés de 0,8 recomendado por Nogueira et al. (1997), .

No início do experimento se incorporou calcário dolomítico (2 $\mathrm{Mg} \mathrm{ha}^{-1}$ ) e gesso (200 $\mathrm{kg} \mathrm{ha}^{-1}$ ) aplicados a lanço em toda a área (incluindo-se entrelinhas) e, a cada 6 meses, realizou-se adubação incorporando-se ao solo, na área de atuação das raízes, $60 \mathrm{~L}$ de esterco de curral, $2 \mathrm{~kg}$ de FOSMAG- $464^{\circledR}$, composto químico à base de fósforo, com a seguinte composição (\%): $\mathrm{P}_{2} \mathrm{O}_{5}=18,0, \mathrm{Ca}=14,0, \mathrm{Mg}=3,5$, $\mathrm{Zn}=0,65, \mathrm{~B}=0,15$ e $\mathrm{Cu}=0,18$, além de $300 \mathrm{~g} \mathrm{planta}^{-1}$ de “FTE BR-12”, composto químico à base de micronutrientes contendo (\%): $\mathrm{Zn}=9,00, \mathrm{~B}=1,80, \mathrm{Cu}=0,8, \mathrm{Mn}=2,00$, $\mathrm{Fe}=3,00$ e $\mathrm{Mo}=0,10$.

Os frutos foram colhidos mensalmente sete meses após a abertura da inflorescência. Após cada colheita se retirava, do total dos frutos colhidos, aleatoriamente, uma amostra de dois frutos por tratamento e por repetição, para avaliação das seguintes variáveis: peso médio do fruto, volume de água de coco, condutividade elétrica da água de coco (CEac), sólidos solúveis totais ( $\left.{ }^{\circ} \mathrm{Brix}\right)$ e $\mathrm{pH}$ da água de coco conforme as metodologias propostas pelo Instituto Adolf Lutz (1985).

Realizaram-se, através do procedimento dos modelos lineares generalizados do SAS as analises estatísticas (SAS Institute, 1995), em que os efeitos dos diferentes níveis de $\mathrm{N}$ e $\mathrm{K}_{2} \mathrm{O}$ sobre as variáveis foram definidos por superfície de resposta e pelos métodos convencionais da análise de variância (teste F), aplicando-se o teste de regressão polinomial.

\section{RESULTADOS E DISCUSSÃO}

Foram observadas, durante o período experimental, condição ambiental adequada para o desenvolvimento do coqueiro; as temperaturas máximas e mínimas foram de 34,6 e $20,2^{\circ} \mathrm{C}$, enquanto as médias variaram de 23,3 a $29,5^{\circ} \mathrm{C}$; a umidade relativa (UR) média do ar oscilou de 68 a $96 \%$ e a evapotranspiração de referência (ETo) de 1,55 a 6,02 mm d-1, com média diária de $4,33 \mathrm{~mm} \mathrm{~d}^{-1}$. A estação chuvosa teve início no mês de janeiro com final em agosto, atingindo uma lâmina acumulada de aproximadamente 1600 mm de chuvas; entretanto, a distribuição foi irregular, sendo a disponibilidade de água controlada mediante as irrigações. Os valores observados estão dentro das faixas ótimas de temperatura (Child, 1974), umidade relativa (Ochs, 1977) e precipitação (Fremond et al., 1975) para o cultivo de coqueiro. Salientase a ocorrência de tendência de aumento da ETo e redução da UR ao longo do ano, em virtude de ocorrer baixa precipitação pluviométrica de julho a dezembro.

Pela análise de variância (Tabela 2) não se constatou efeito significativo das variáveis independentes sobre o peso de fruto mas, sim efeito significativo das doses de $\mathrm{N}$ para o 
volume, $\mathrm{pH}$ e ${ }^{\circ}$ Brix da água de coco; as doses de $\mathrm{K}_{2} \mathrm{O}$ exerceram efeito significativo sobre a condutividade elétrica (CEac) e o ${ }^{\circ}$ Brix da água de coco, resultados que divergem de Silva et al. (2006) que, nos $4^{\circ}$ e $5^{\circ}$ anos de cultivo com aplicação de doses correspondentes à metade das aplicadas neste trabalho, encontraram efeito conjunto quadrático dos dois nutrientes no peso de frutos, volume, ${ }^{\circ}$ Brix e CEac da água de coco e efeito isolado do potássio nos valores de $\mathrm{pH}$ da água.

$\mathrm{O}$ incremento de $\mathrm{N}$ na fertirrigação exerceu efeito significativo $(P \leq 0,01)$ na redução do volume da água de coco (Figura 1A). Em geral o volume da água de coco apresenta, comportamento semelhante ao peso do fruto, porém no presente estudo frutos de maior peso não acumularam volumes maiores de água de coco, portanto, os frutos foram favorecidos discretamente pelas doses de $\mathrm{N}$ no maior desenvolvimento do mesocarpo em detrimento da menor cavidade interna de frutos, o que não é desejável, pois o espaço interno da cavidade é atributo de qualidade dos frutos verdes do coqueiro Anão possibilitando maior capacidade de armazenamento de água de coco. Os resultados estão de acordo com Teixeira et al. (2005) e Silva et al. (2006), quando afirmam que o aumento das doses de $\mathrm{N}$ provoca diminuição no volume de água de coco. Observa-se, contudo, que o volume médio de água de coco ficou acima de $450 \mathrm{~mL}_{\text {fruto }}^{-1}$ atingindo o valor máximo próximo de $500 \mathrm{~mL}$, em menor dose de N. Comparativamente, esses resultados são superiores aos valores médios de 384,26 mL relatados em Camboim Neto (2002); 258 mL obtidos por EMPARN (2001) em frutos com seis meses de idade e 394,65 mL obtidos por Aragão et al. (2001).

Tabela 2. Resumo da análise de variância (teste F) para componentes de qualidade dos frutos de coco verde

\begin{tabular}{|c|c|c|c|c|c|}
\hline \multirow{2}{*}{ Fonte de variação } & \multicolumn{5}{|c|}{ Teste F\# } \\
\hline & Peso & Vol. & $\mathrm{pH}$ & CEac & ${ }^{\circ}$ Brix \\
\hline Linear N & ns & $\star \star$ & ** & ns & $\star \star$ \\
\hline Quadrático N & ns & ns & ns & ns & ns \\
\hline Linear K & ns & ns & ns & ns & $\star \star$ \\
\hline Quadrático K & ns & ns & ns & ** & $\star *$ \\
\hline Linear $N^{*} \mathrm{~K}$ & ns & ns & ns & ns & ns \\
\hline C.V(\%) & 3,00 & 4,01 & 1,75 & 0,72 & 2,11 \\
\hline
\end{tabular}

\# ns Não significativo $e^{*},{ }^{* *}$ significativo a 0,05 e 0,01 de probabilidade pelo teste $\mathrm{F}$, respectivamente

Verificou-se no pH da água de coco, o efeito significativo das doses de nitrogênio aplicadas na fertirrigação mas não se registrou influência do potássio sobre esta variável. $\mathrm{O}$ pH da água de coco (Figura 1B) aumentou de 5,65 a 5,80 em relação às doses de nitrogênio, em que os resultados estão coerentes com os obtidos por outros autores, para os quais o pH da água de coco se situa entre 4,5 a 5,7; trabalho conduzido pela EMPARN (2001) indicou que o pH da água de coco varia de 4,6 a 5,8 do $5^{\circ}$ ao $9^{\circ}$ mês após a abertura de inflorescência atingindo o valor máximo no $7^{\circ}$ mês. Para Kumar et al. (1975) o pH da água de coco varia de 4,8 a 5,2 em frutos com idade entre 6 e 12 meses, enquanto para Tavares (1998) o sabor doce e a adstringência desejável da água de coco são atingidos com pH próximo a 5,6 em frutos com idade de 8 a 12 meses. O pH baixo tem maior importância, caso o fruto se destine ao processo industrial, como no caso de engarrafamento, face à inibição do crescimento bacteriano em soluções ácidas.

A condutividade elétrica da água de coco não sofreu efeito pela adição de nitrogênio mas decresceu significativamente $(\mathrm{P} \leq 0,01)$ com o incremento da dose de potássio na água de irrigação (Figura 1C). Neste contexto, salienta-se que a função estabelecida tem a validade até a dose de 4000 g de $\mathrm{K}_{2} \mathrm{O}$ planta $^{-1}$ ano $^{-1}$, pois o aumento em CEac indicado após esta dose, não tem amparo biológico.
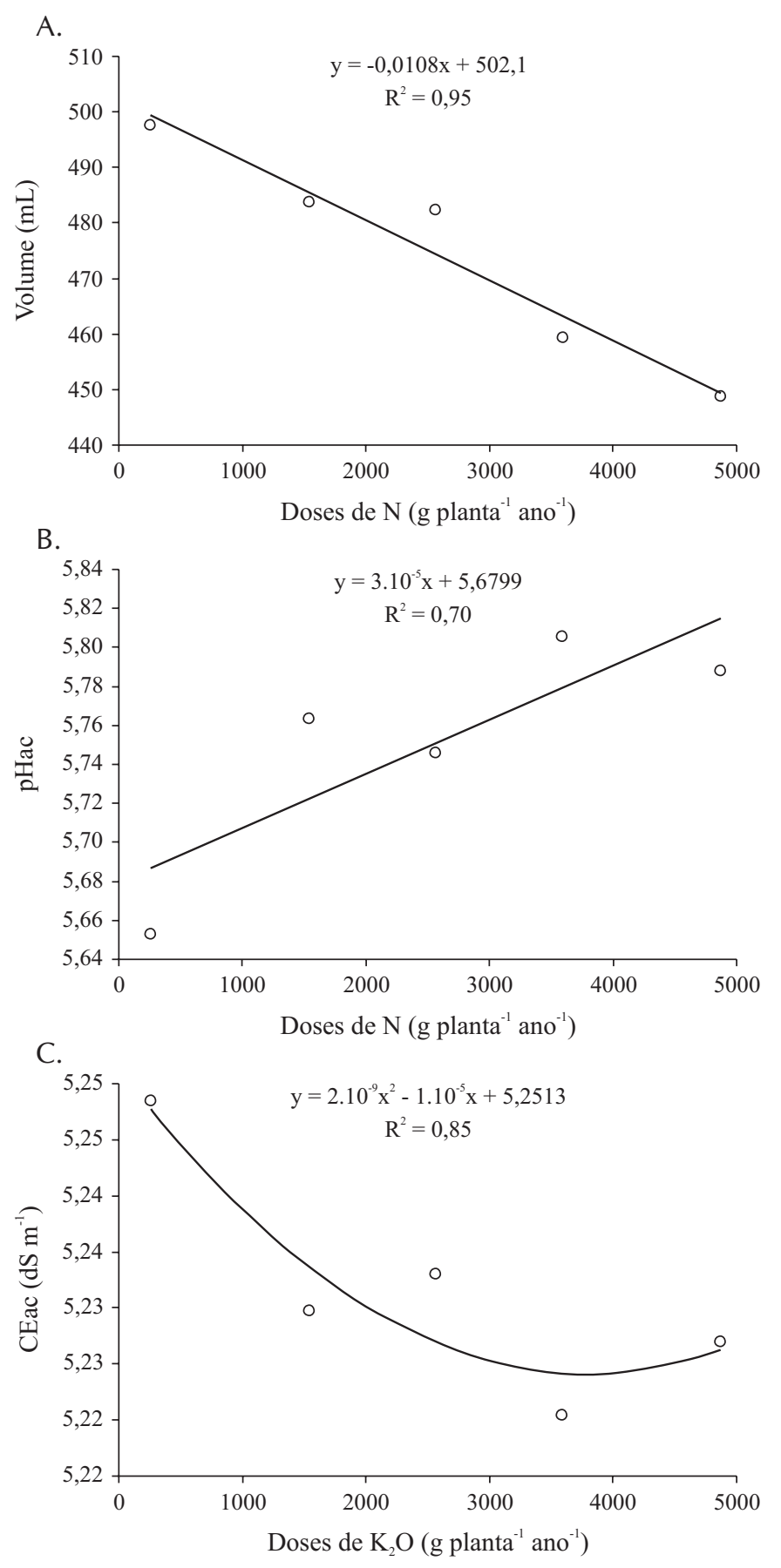

Figura 1. Comportamento dos valores médios de volume (A), $\mathrm{pH}(\mathrm{B}) \mathrm{e}$ conduitividade elétrica da água de coco - CEac (C) em função de doses de $\mathrm{K}_{2} \mathrm{O}$ e $\mathrm{N}$ aplicadas via fertirrigação 
Doses de $\mathrm{K}_{2} \mathrm{O}$ (superiores a 3000 g planta $^{-1} \mathrm{ano}^{-1}$ ) na fertirrigação do coqueiro, resultaram em menores valores de condutividade elétrica da água de coco com valores médios em torno de $5,23 \mathrm{dS} \mathrm{m}^{-1}$ (Figura 1C). Os resultados diferem dos constatados por Silva et al. (2006) ao revelarem que a CEac diminui com o aumento das doses de $\mathrm{N}$ e aumenta de forma quadrática com as doses de K; essas diferenças, provavelmente, se devem ao efeito quantitativo das doses, conforme já mencionado. Camboim Neto (2002), trabalhando com lâminas de irrigação no coqueiro, revela uma CEac média de $5,57 \mathrm{dS} \mathrm{m}^{-1}$ em água de frutos com 7 meses e ainda que o incremento na lâmina de água de irrigação reduz o valor dessa variável na água de coco, embora se trate de uma diferença de apenas $0,03 \mathrm{dS} \mathrm{m}^{-1}$.

$\mathrm{O}{ }^{\circ}$ Brix representa a percentagem de sólidos solúveis totais incluindo-se os ácidos e os açúcares. Os nutrientes ( $\mathrm{N}$ e K) exerceram efeitos distintos sobre esta variável. Verifica-se, na Figura 2, que o aumento de quantidade de $\mathrm{K}_{2} \mathrm{O}$, via fertirrigação, resultouna elevação do ${ }^{\circ} \mathrm{Brix}$ da água de coco, sendo o maior valor de ${ }^{\circ} \mathrm{Brix}$ notado no tratamento com a maior dose de $\mathrm{K}_{2} \mathrm{O}$ (4872 g planta $^{-1}$ ano $\left.^{-1}\right)$ foi 6,91. Por outro lado, o incremento da dose de nitrogênio na fertirrigação diminuiu o valor do ${ }^{\circ}$ Brix na água de coco. Essa situação pode ser resultado de interação antagônica entre nitrogênio e potássio em que doses elevadas de $\mathrm{N}$ promove diminuição de disponibilidade de $\mathrm{K}$ às plantas (Malavolta et al., 1997). Fernandes et al. (1992) verificaram uma redução na porcentagem de sólidos solúveis na polpa do mamão em função de aumentos na taxa de adubação nitrogenada, apresentando redução linear na porcentagem de sólidos solúveis (Marinho et al., 2001). Todavia, os valores de ${ }^{\circ}$ Brix encontrados no presente estudo, estão dentro de faixa normal e pouco superior aos valores observados por Lima et al. (2004), que encontraram o valor médio em torno de 5,5 em condições edafoclimáticas do Rio de Janeiro.

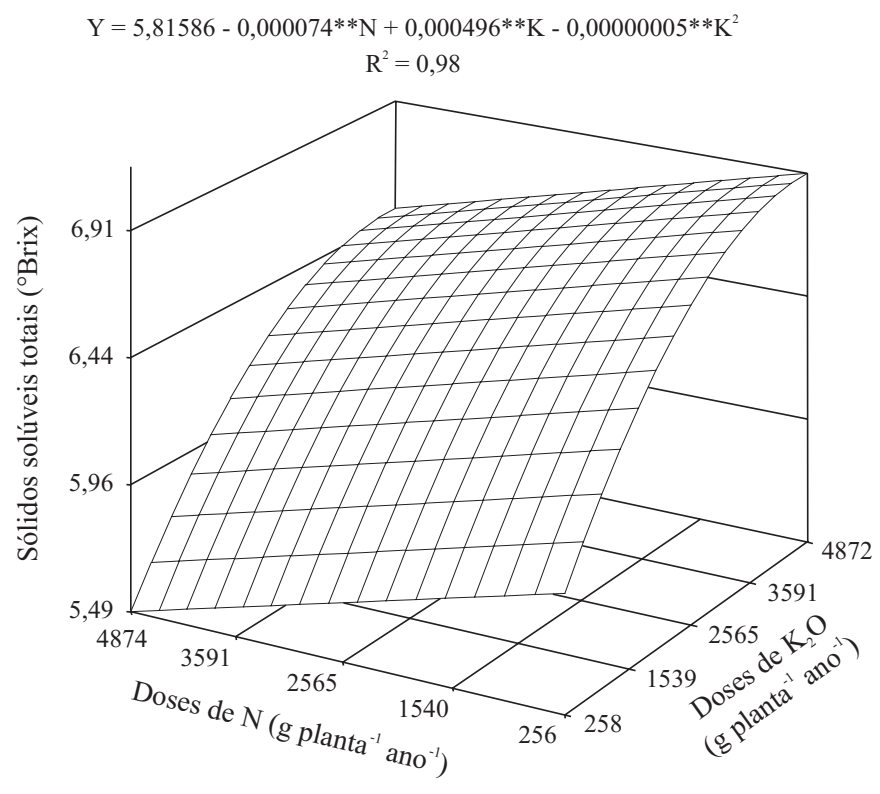

Figura 2. Superfície de resposta relacionando o ${ }^{\circ}$ Brix da água de coco com doses de potássio e nitrogênio, aplicadas via fertirrigação
Apesar das pequenas diferenças numéricas entre os valores de ${ }^{\circ}$ Brix, em termos percentuais, existe uma amplitude de $20 \%$ entre o maior e o menor valor observado. Valores de ${ }^{\circ}$ Brix acima de seis para água de coco proporcionam sabor agradável e de grande aceitação pelo mercado; esta é, também, uma vantagem para a indústria de envasamento de água de coco que, em algumas situações, adiciona adoçantes, como a frutose, para agregar qualidade à bebida e proporcionar maior palatabilidade ao produto.

Os efeitos do aumento do potássio na fertirrigação refletiram em aumento de sólidos solúveis (açúcares - ${ }^{\circ}$ Brix) e na redução da salinidade da água de coco, denotando padrão de qualidade pela medida da condutividade elétrica da água de coco (CEac) que pode ser considerada de grande importância em virtude de influir no sabor e no valor nutritivo da água de coco.

\section{CONCLUSÕES}

1. As doses de nitrogênio e potássio não afetaram o peso médio do fruto verde de coco.

2. $\mathrm{O}$ aumento do nitrogênio na fertirrigação elevou o pH e diminuiu o volume e o teor de sólidos solúveis ( ${ }^{\circ}$ Brix) da água de coco.

3. O aumento das doses de potássio reduziu a salinidade (CEac), mas aumentou o teor de sólidos solúveis ( ${ }^{\circ}$ Brix) da água de coco.

\section{LITERATURA CITADA}

Allen, R. G.; Pereira, L. S.; Raes, D.; Smith, M. Crop evapotranspiration: gigelines for computing crop water requirements. Rome: FAO, 1998. 300p. Irrigation and Drainage, Paper 56.

Anuário Estatístico do Brasil. Rio de Janeiro: IBGE, v.64, 2004.s.p.

Aragão, W. M.; Cruz, E. M. O.; Helvécio, J. S. Caracterização morfológica do fruto e química da água de coco em cultivares de coqueiro anão (Cocos nucifera L. var. Nana). Revista Agrotrópica, v.13, n1, p-56-70, 2001.

Ayers, R. S.; Westcot, D. W. Qualidade da água na agricultura. 2.ed. Campina Grande: UFPB, 1999, 152p. FAO. Estudos de Irrigação e Drenagem, 29.

Camboim Neto, L. de F. Coqueiro anão verde: influência de diferentes lâminas de irrigação e de porcentagens de área molhada no desenvolvimento, na produção e nos parâmetros físicoquímicos do fruto. Viçosa: UFV, 2002. 121p. Tese Doutorado

Child, R. Coconut. London: Longman, 1974. 335p.

EMBRAPA - Empresa Brasileira de Pesquisa Agropecuária. Centro Nacional de Pesquisa de Solos. Manual de métodos de análise de solos. 2.ed. rev. e atual. Rio de Janeiro: EMBRAPA, 1997. 212p.

EMPARN. Caracterização física do fruto e composição química da água de coco de cultivares Anão verde do Jiqui, Anão amarelo e Híbrido PB 121 aos 5, 6, 78 e 9 meses de idade. In: "Mini-curso" O cultivo do coqueiro. Fortaleza: FRUTAL, 8, 2001. 102p.

R. Bras. Eng. Agríc. Ambiental, v.11, n.5, p.453-458, 2007. 
FAO. FAOSTAT. http://apps.fao.org. Jan. 2005.

Fernandes; D. M.; Correa, L. S.; Fernandes, F. M. Efeito da adubação nitrogenada e fosfatada em mamoeiro (Carica papaya L.) 'Solo’ cultivado com irrigação. Científica, v.18, p.1-8, 1992.

Fontes, H. R. Perspectivas para a produção de biodiesel a partir de óleo de coco. http://www.ambienteemfoco.com.br/?p=774. 20 Abr.2007.

Fremond. Y.; Ziller, R.; Lamothe, M. N. El Cocotero. Barcelona: Blume, 1975. 236p. Coleccion Agricultura Tropical

Frizone, J. A.; Zanini, J. R., Paes, L. A. D.; Nascimento, V. M. Fertirrigação mineral. 1.ed. Ilha Solteira: UNESP, 1985, v.1, 31p.

Instituto Adolf Lutz. Métodos físicos e químicos para análises de alimentos. São Paulo: IAL, 1985. 533p.

Lima, E.; Silva, J. Q.; Morais, R. F.; Barbosa, M. A. D.; D’Agostini, F. S. Caracterização fisico-quimico da água de fruto do coqueiro anão verde, produzido no litoral sul de Rio de Janeiro. In: FERTIBIO, 2004. Lages. Anais..., Lages:UDESC/ SBCS, 2004. CD Rom

Kumar, B. J.; Shetty, S. N.; Gowda, D. K. V. Electrolyte content of coconut water as influenced by age of coconut. Indian Veterinary Journal, v.52, p.38-42, 1975.

Magat, S. Coconut. In: World fertilizer use manual. International Fertilizer Association. 2005.http://www.fertilizer.org/ifa/publicat/html/pubman/coconut.htm. 11 Abr 2005.

Malavolta, E.; Haag, H. P.; Mello, F. A. F.; Brasil Sobrinho, M. O. C. Nutrição mineral e adubação de plantas cultivadas. São Paulo: Pioneira, 1974. p.668-685.

Malavolta, E.; Vitti, G. C.; Oliveira, S. A. Avaliação do estado nutricional das plantas: Princípios e aplicações. 2.ed. Piracicaba: POTAFOS, 1997. 319p.

Marinho, C. S.; Oliveira, M. A. B.; Monnerat, P. H.; Vianni, R.; Maldonado, J. F. Fontes e doses de nitrogênio e a qualidade dos frutos do mamoeiro. Scientia Agricola, v.58, n.2, p.345-348, 2001.

Menon, R. P. V.; Pandalai, R. M. The coconut palm. Ernakulam: Indian Central Coconut Committee, 1958. 384p. Monograph

Nogueira, L. C.; Nogueira, L. R. Q.; Miranda, F. R. Irrigação do coqueiro. In: Ferreira, J. M. S.; Warwick, D. R. N. Siqueira, L. A. A cultura do coqueiro no Brasil. 2.ed. Brasília, EmbrapaSPI; Aracaju, Embrapa-CPATC, 1997. p.159-187.
Ochs, R. Les contraintes écologiques du dévelopment des oléagineus pérennes (palmier et cocotier) em Afrique Occidentale et Centrale. Oléagineux, v.32, n.11, p.461-477, 1977.

Ouvrier, M. Exportation par la récolte du cocotier PB-121 em function de la fumure potassique et magnésienne. Oléagineux, v.39, n.5, p.263-271, 1984.

Papadoupolos, I. Fertirrigação: Processo de transição da fertirrigação convencional para a fertirrigação. In: Folegatti, M. V.; Casarini, E.; Blanco, F. F.; Brasil, R. P. C. do.; Resende, R. S. (coord.) Fertirrigação: Flores, frutas e hortaliças. Guaíba: Agropecuária, 2001. cap.1, p.9-70.

Santos e, H. G.; Jacomine, P. K. T.; Anjos, L. H. C.; Oliveira, V. A.; Oliveira, J. B.; Coelho, M. R.; Lumbreras, J. F.; Cunha, T. J. F. (ed.) Sistema brasileira de classificação de solos. 2.ed, Rio de Janeiro: Embrapa Solos, 2006. 306p.

SAS Institute. Statistical analysis system for windows: Computer program manual. Cary, 1995.705p.

Silva, R. A. da; Cavalcante, L. F.; Holanda, J. S. de; Pereira, W. E.; Moura, M. F. de; Ferreira Neto, M. Qualidade de frutos do coqueiro-anão verde fertirrigado com nitrogênio e potássio. Revista Brasileira de Fruticultura, Jaboticabal, v.28, n.2, p. 310-313, 2006.

Sobral, L. F. Nutrição e adubação de coqueiro. In: Ferreira, J. M. S.; Warwick, D. R. N.; Siqueira, L. A. A cultura do coqueiro no Brasil. 2.ed. Aracaju: Embrapa CPATC, 1998. p.129-157.

Sobral, L. F. Nutrição e adubação. In: Fontes, H. R.; Ribeiro, F. E.; Fernandes, M. F. (ed.) Coco: Produção. Brasília: EMBRAPA, 2003, p.41-52.

Tavares, M. Estudo da composição química da água de coco anão verde em diferentes estágios de maturação. In: Congresso Brasileiro de Ciência e Tecnologia de Alimentos, 16. 1998 Rio de Janeiro. Anais... Rio de Janeiro: SBCTA, 1998. v.2, p.1262-1265.

Teixeira, L. A. J.; Bataglia, O. C.; Buzetti, S.; Furlani Jr., E.; Isepon, J. dos S. Adubação com NPK em Coqueiro-Anão Verde (Cocos nucifera L.): Rendimento e qualidade de frutos. Revista Brasileira de Fruticultura, Jaboticabal, v.27, n.1, p.120123, 2005. 